\title{
Marrying Out: Trends and Patterns of Mixed Marriage amongst Qataris
}

\author{
Sanaa T. Alharahsheh ${ }^{1}$, Mohamad M. Mohieddin ${ }^{1} \&$ Feras K. Almeer ${ }^{1}$ \\ ${ }^{1}$ Doha international Family Institute/Qatar foundation. ${ }^{1 *}$ \\ Correspondence: Sanaa T. Alharahsheh, Doha international Family Institute/Qatar foundation.
}

Received: October 9, 2015

Accepted: October 16, 2015

Available online: October 27, 2015

doi:10.11114/ijsss.v3i6.1121

URL: http://dx.doi.org/10.11114/ijsss.v3i6.1121

\begin{abstract}
Social scientists have extensively studied mixed marriage in its different forms since the beginning of the past century, especially in the western societies. While there is a considerable body of international literature pertaining to mixed marriage, very little research has been conducted on mixed marriage in the Arab region in general and in the Gulf Cooperation Council (GCC) area in particular. Virtually, no empirical study to our knowledge has examined mixed marriage in Qatar. The purpose of this study is thus to analyze and outline the trends and patterns of mixed marriage among Qatari nationals. The results indicated that although the endogamous marriage (Qataris males married to Qatari females) is the main marriage pattern among the Qatari population, mixed marriage in Qatar is on the rise. Mixed marriage among Qatari males compared to Qatari females has increased systematically since 1985. In addition, Qatari females are more likely than males to marry someone from the other GCC area. Meanwhile, in the last few years Qatari males have tended to marry from outside the GCC countries, mainly from other Arab countries. Social, demographic, and cultural implications of mixed marriage among Qataris need to be a central focus for family policy.
\end{abstract}

Keyword: Mixed marriage, endogamous marriage, trends, patterns, Qatar, GCC countries

\section{Introduction}

Research on mixed marriage in Western societies has a very long scientific tradition, dating back to the beginning of the twentieth century. While there is a considerable body of international literature pertaining to mixed marriage (e.g. Oganesyan, 2014; Kulu1 \& González-Ferrer, 2014; Goli, Singh, \& Sekher, 2013; Lanzieri, 2012 a, b, c; Collet, 2012; Singh \& Goli, 2011; Muttarak \& Heath, 2010; Aldridge, 1973; Becker ; Burma, 1963; Panunzio 1942; Bassard, 1939; and Drachsler, 1921), very little research has been conducted on mixed marriage in the Arab region in general and in the Gulf Cooperation Council (GCC) area in particular. To the best of our knowledge, there is not a single empirical study that examined mixed marriage in Qatar. As such, the current research will constitute the first ground-breaking contribution of its kind on Qatari mixed marriage. Hence, the overall objectives of this research are to present the latest available information on mixed marriages among Qataris covering the period from the 1985 - 2013; to analyze and outline the trends and the patterns of mixed marriages among Qataris, covering the period from the 1985 - 2013; and to provide knowledge base for policy debate and formulation. The added value of this paper stems not only from the fact that there have been no previous attempts to study the phenomenon, but also because of its demographic, social, cultural and policy implications for Qatar, such as the high percentage of never married women and the decreasing fertility rate (Ucar, Al Harami and Leet, 2011; Qatar Statistic Authority, 2013). In addition, knowledge gained from this study can act as a catalyst to give rise to other research projects on mixed marriage within the GCC countries and at the Arab regional level.

There is no consensus among social scientists on a single definition of the term mixed marriage (Varro, Streiff-Fenart, \& Philippe, 1994). Literature is full of a variety of terms of mixed marriage that are used interchangeably, such as interracial marriage, intercultural or cross-cultural marriage, inter-faith marriage, and inter-national marriage. Interracial marriage is a term used to describe a marriage that occurs between two people from different races or ethnicities, like the marriage between people of African descent and Caucasians. Intercultural or cross-culture marriage is a marriage that takes place between two people from different cultures, such as a marriage between a man raised in Japan and a

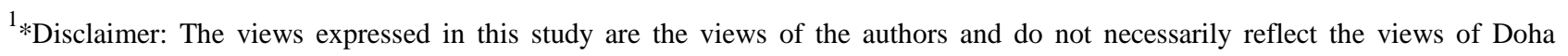
International Family Institute.
} 
raised in the UK. Inter-faith marriage is a marriage between partners from different religions or sects, like the marriage between a Muslim man and a Christian woman. International marriage is a marriage between two people from different nationalities (Lanzieri, 2012 a; Jo-Pei, 2012, Collet, 2011, Qian, 2005; Neyrand, \& M'Sili, 1998; Kalmijn, 1998; Harmsen, 1999; Petersen, 1986). In this paper the term mixed marriage is operationally defined as a marriage contracted between spouses where by only one of them, either male or female, is a Qatari and the contract took place in Qatar. Hence, this research focuses on mixed marriages among Qatari nationals, and does not take into account those marriages that take place between foreign populations living in Qatar and marrying across ethnic, racial, religious and/or national lines, or even those Qataris who married outside their home country or registered their union in Qatar's embassies abroad. This is justified on the grounds that such unregistered cases with the government and its respective agencies will not figure into the national statistics.

Generally, individuals have the tendency to marry within the same group, especially when potential spouses are similar to them in terms of education, values, religion, culture, and socio-economic status, yet there are always individuals who marry across the boundaries of their social groups. The frequency of mixed marriages has often been considered a type of marriage that fosters social integration and promotes social and cultural change. (Oganesyan, 2014; Kulu1 \& González-Ferrer, 2014; Goli, Singh, \& Sekher, 2013; Lanzieri, 2012a, b,c; Singh, \& Goli, 2011; Muttarak and Heath, 2010; Garcia, 2006; O’Donoghue, 2004; Nave, 2000; Kalmijn 1998).

Throughout history, people of differing cultures, nationalities, ethnicities, and faiths have intermarried and lived together, (Goli, Singh, \& Sekher, 2013; Singh, \& Goli, 2011; Coleman 1994). With the increasing impact of modernization, globalization, and international migration in the contemporary societies mixed marriages are more frequent these days and on the rise worldwide. In the USA, for example, interracial marriage was illegal before 1967, and there were ramifications for anyone who married interracially (Honeycutt, Lane, Pea, Taylor \& Guchte, 2005). In the last few decades, however, marriage across racial and ethnic lines in the USA has become more popular (Yee, 2012; Wang, 2012). According to recent studies, interracial marriage in the USA has increased significantly from $0.4 \%$ of all marriages in 1960 to $3.2 \%$ in 1980 and reached 8.4\% in 2010 (Lewis, 2014; Wang, 2012).

Evidence from other parts of the world also suggests an increase in mixed-marriages. In Europe, for instance, Lanzieri (2012 a, b, c) has estimated the percentage of mixed marriages in 30 European countries (Note 1) over recent years and found that mixed marriages are inching up in most European countries. On average, 1 in every 12 cases of marriage in Europe was mixed from the years 2008 to 2010 . However, there is evidence of significant variation in the level between countries. Mixed marriages are higher in countries like; Luxembourg, Switzerland, the Baltic States, Scandinavia, Belgium, the Netherlands, Germany, United Kingdom, and France than they are in places like; Spain, Italy, and South East Europe.

The increasing frequency of mixed marriage is not restricted to the Western World. In the Arab region, mixed marriages are also very common. In Lebanon, for example, while accurate statistics on the rate of mixed marriages are hard to come by, anthropological evidence suggest that they are on the rise (Tarabey, 2013). In 2013, the percentage of mixed marriages in Lebanon had reached about 15\% of all registered marriage contracts (information - International, 2013). The available statistics from the GCC countries indicate that rates of mixed marriage are as high as $28.9 \%$ in Bahrain, 18.9\% in Kuwait, 28.9\% in United Arab Emirates, and 23.1\% in Qatar (Qatar Statistic Authority, 2013; UAE National Bureau of Statistics, 2013; State of Kuwait Central Statistical Bureau, 2013; kingdom of Bahrain Central Informatics Organization, 2013). Evidently, mixed marriages are increasing worldwide and Qatar is no exception to this reality.

Qatar is an independent Arab country that is located in the Arabian Peninsula in southwest Asia. It extends from the mainland of the Arabian Peninsula adjacent to the eastern coast of Saudi Arabia (Alrouh, Ismail, \& Cheema, 2013; Sandridge, Takeddin, AL-kaabl, \& Frances, 2010). Prior to 1940, Qatar's economy was based on pearl fishing and dates agriculture and trades. Since then, the country has witnessed major structural socio-economic, political, and demographic transformations, resulting from the discovery of oil and natural gas reserves. This has led to massive changes that touch upon all the aspects of life, including the structures, functions, and roles of the family (Alrouh, Ismail, \& Cheema, 2013; Bener, 2012; Hanieh, 2011; El-Haddad, 2003).

Qatar has one of the fastest-growing populations in the world due to the immigration of foreign workers. According to the 2013 population census, the population was about 1.8 million, of which 278,000 were Qatari citizens and 1.5 million were expatriates, leaving Qatari nationals at less than $15 \%$ of the total population (Qatar Statistics Authority, 2013). In 2013, Qatar has been classified as a country with a very high human development, with HDI (0.834) (UN, 2013); one of the highest GDPs per capita in the world due to the growth of its hydrocarbon industry, especially oil and gas; and one of the fastest growing economies in the world. Therefore, Qatar is ranked as one of the wealthiest countries in the world (Alrouh, Ismail, \& Cheema, 2013).

In recent years, Qatar had been transformed into a modern state with modern facilities and infrastructure. The 
government of Qatar has put much emphasis on the expansion of education for all parts of society. Women's education, the standard of living, women's participation in the paid labor force has all improved immensely. In 2007 and according to Qatar Statistics Authority, the ratio of female and male students is relatively equal at primary and secondary levels. The increase in the ratio of female students at university level is, however, clear and remarkable (QSA. 2008). In this respect, female student constituted about $70 \%$ of all university students in Qatar compared to $30 \%$ for their male counterparts. This is partly explained by the preference of male students to join the labor market immediately after obtaining their secondary school diploma and the greater tendency of those who chose to complete their university education to join universities abroad. On the other hand, females see in university education, in addition to its classic functions, a major opportunity to go out of their homes.

On female labor force participation data shows that economic growth has had its positive impacts on their economic activity rates. Despite the general growth, the gap is still very clear between females and males as the economic activity rate for males (15+) reached $94.5 \%$ compared to $49.3 \%$ for females. The proportional distribution of economically non-active females has fallen from $72.5 \%$ in 1986 to 50.7\% in 2007 (Jakobsen, 2010, p 31).

Health and main demographic indicators such as life expectancy, infant and child mortality, and maternal mortality have also improved greatly (State of Qatar Ministry of Development Planning and Statistics, 2012). The social system in Qatar is structured around the family. Like most other countries in the Arab world, the marriage system in Qatar is virtually endogamous and usually arranged. Marriages between Qataris and other non-Qatari GCC citizens are also popular. Yet, as a result of increasing globalization, international migration, technological developments and their accompanied social transformation that are dramatic in pace and effect, Qatari families are undergoing major changes, as new patterns of marriage and family formation emerge (Layachi, 2013; El-Haddad, 2003). Amidst these changes is spouse selection, whereby it is noted that mixed marriages in Qatar have been on the rise (QSA, 2013).

The paper consists of five sections. Following this introduction to the study, section two discusses the changing economy and demography of Qatar. The third section presents data sources of the paper, a discussion of its limitations, and the method used in data analysis. The fourth section presents an analysis of the limited data available and draws some conclusions related to gender differences in the current trends of mixed marriage in Qatar today. Finally, in the conclusion we attempt to draw some policy recommendations concerning mixed marriage in Qatar.

\section{The Changing economy and demography of Qatar}

When the exploitation of Qatari oil fields started in 1949, the country had hardly 16,000 inhabitants (De Bel-Air, 2014), a notable decrease from the estimate of 27,000 recorded a century earlier (Lorimer, 1908). The invention of the artificial pearl by the Japanese in the 1920 's led to the collapse of the traditional economy based on pearling and trade ${ }^{2}$. This was coupled by economic and political tensions with Bahrain in the 1930s. These developments pushed the small Qatari population, primarily composed of local semi-nomad and nomad Bedouin tribes, fishermen, merchant families with slaves, and a few thousand of Persian origin to migrate inland primarily to Eastern and Southern Saudi Arabia. Qatar's ruling family and the British Protectorate authorities who set up the oil sector resorted to importing workers from the Indian subcontinent and the Arab Middle East, due to the local manpower's low level of literacy and industrial skills. In 1970, shortly before Qatar gained independence in 1971, the first census was conducted. It yielded a total population of 111,113, of which 45,039 (40.5\%) were Qataris and 66,094 (59.5\%) foreigners (De Bel-Air, 2014: 3-4).

Since then the population of Qatar has continued to grow at a phenomenal rate. By the advent of 1980 the population of the country had reached about 224 thousand inhabitants (ESCWA, 2009) and was estimated to hover around 1.732,718 in 2011, amounting to15-fold increase in 40 years (State of Qatar, Permanent Population Committee, 2012). Further, official sources put the population size at about an estimated 2,374,860 in the $31^{\text {st }}$ of May 2015 (QSA, 2015). Table 1 shows the population size of Qatar its average annual growth rates between 1980 and 2015 and its projected growth from 2015 up to 2050.

Table 1. Estimates and Projected Population Size of Qatar by Sex and average annual growth rates, 1980-2050 (in Thousands)

\begin{tabular}{cccccc}
\hline Year & Males & Females & Total & Interval Period & Average Annual Growth Rate (\%) \\
\hline 1980 & 141 & 83 & 224 & --- & -- \\
1985 & 248 & 123 & 371 & $1980-1985$ & 10.12 \\
1990 & 319 & 157 & 477 & $1985-1990$ & 5.01 \\
1995 & 330 & 171 & 501 & $1990-1995$ & 1.01 \\
2000 & 386 & 207 & 594 & $1995-2000$ & 3.39 \\
2005 & 547 & 274 & 821 & $2000-2005$ & 6.49 \\
2010 & 1,325 & 424 & 1,750 & $2005-2010$ & 15.13 \\
\hline
\end{tabular}




\begin{tabular}{llllll}
\hline $2015^{*}$ & 1,797 & 554 & $2,351^{* *}$ & $2010-2015$ & 5.90 \\
$2020^{*}$ & 1,921 & 622 & 2,543 & $2015-2020$ & 1.57 \\
$2025^{*}$ & 1,988 & 674 & 2,662 & $2020-2025$ & 0.92 \\
$2030^{*}$ & 2,043 & 717 & 2,760 & $2025-2030$ & 0.72 \\
$2035^{*}$ & 2,086 & 756 & 2,842 & $2030-2035$ & 0.59 \\
$2040^{*}$ & 2,118 & 793 & 2,912 & $2035-2040$ & 0.48 \\
$2045^{*}$ & 2,134 & 829 & 2,962 & $2040-2045$ & 0.35 \\
$2050^{*}$ & 2,125 & 860 & 2,985 & $2045-2050$ & 0.15 \\
\hline
\end{tabular}

Source: United Nations, World Population Prospects: The 2012 Revision, Available at:

http://esa.un.org/unpd/wpp/unpp/panel_indicators.htm * Projections (medium variant)

** There is a difference between the estimate of UN World Population Prospects and that of Qatar population Authority stated in the test of about 23 thousands amounting to about $1 \%$.

It is clear from the table that the population of Qatar is going to continue to grow in absolute terms in the foreseen future, and is predicted to reach approximately 3 million by the year 2050. Despite this, it is worth noting that there have been vast variations in its average annual growth rates between 1980 and 2015, ranging from an estimated high of $15 \%$ between 2010-2015, to a low of 1\% during the 1990-1995 interval periods. It's average annual growth rates are also expected to witness a considerable slowdown in the future to the point of almost no growth by the advent of 2050. This is the result of both declining fertility and migration. Projections show that total fertility was estimated to decline down from an average of 4.45 per woman between 1980-1985 to reach an estimated 2.05 (Replacement fertility level is 2.1) children per woman in 2010-2015. Furthermore, it is projected to keep on declining to reach 1.67 children per woman in the 2045-2050 period. This is predicted to be accompanied by declining Infant mortality rates, under Five-child mortality rates as well as maternal mortality rates. In these respects, the Infant Mortality Rate of the Qatari Population, which was estimated at 23.2 infant deaths per 1,000 live births in 1980-1985, had decreased to 7.5 infant deaths per 1,000 live births in 2005-2010. It is further projected to continue this downward trend to reach 3.5 infant deaths per 1,000 live births in 2045-2050. By the same token, under-Five Child mortality rate has also been on the decline down from an estimated 31 deaths per 1,000 live births in 1980- 1985, and decreased to 8 between 2010-2015. It is projected to continue deceasing to reach 4 deaths per 1,000 live births by 2050. Similarly, maternal mortality rate in Qatar was estimated at 15 maternal deaths per 100,000 live births in 1990. It has decreased to reach 7 maternal deaths per 100,000 live births as 2010 (UN, World Population Prospects, the 2012 Revision). Statistics demonstrate quite clearly that Qatar has been witnessing mortality and fertility transitions since the 1980's.

It is, however, international migration that accounts for population change in Qatar. According to the United Nations the estimated population of Qatar in 1950 was about 25,000. The population pyramid of the country at the time assumed the classic shape of less developed countries, a broad base, a narrow tip, and an almost even gender distribution. By 1960, the population of the country almost doubled to reach 47,000 and in in 1970, a year before the country was declared an independent state, it had reached 108,000 . These figures amount to average per annum population growth rates of $6.25 \%$ and 8.68\% during the 1950-1960 and 1960-1970 intervals respectively (UN, World Population Prospects: The 2012 Revision) which are far above the almost stable and probably negative growth rates that prevailed since Lorimer had given his estimate of 27,000 in 1908, and that of the UN for 1950. Table 2 gives the details of net and projected migration to Qatar between 1980 and 2050.

Table 2. Net migration to Qatar 1980-2050

\begin{tabular}{ccc}
\hline Interval Period & Rate Per 1000 population & Number in thousands \\
\hline $1980-1985$ & 68.6 & 20 \\
$1985-1990$ & 27.1 & 12 \\
$1990-1995$ & -9.2 & -4 \\
$1995-2000$ & 15.7 & 9 \\
$2000-2005$ & 48.2 & 34 \\
$2005-2010$ & 133.4 & 171 \\
$2010-2015$ & 48.8 & 100 \\
$2015-2020$ & 7.3 & 18 \\
$2020-2025$ & 2.7 & 7 \\
\hline
\end{tabular}




\begin{tabular}{llll}
\hline $2025-2030$ & 2.6 & 7 \\
$2030-2035$ & 2.5 & 7 & 7 \\
$2035-2040$ & 2.4 & 7 & 7 \\
$2040-2045$ & 2.3 & 7 \\
$2045-2050$ & 2.3 &
\end{tabular}

Source: United Nations, World Population Prospects: The 2012 Revision, Available on:

http://esa.un.org/unpd/wpp/unpp/panel_indicators.htm * Projections (medium variant)

As can be seen from the table the annual net migration has been systematically rising since 1985, with the exception of the interval periods of 1985 -1990 and 1990-1995. In the first of these two intervals the rate and numbers dropped but were still in the positive side. During the second interval they witnessed negative growth. Since then the rate rose from 15.7 per 1000 in 1995-2000 to reach 133.4 migrants per 1,000 in the 2005-2010 interval, signaling higher migration inflows. Nonetheless, it is projected that the annual rate of net migration is dropping in the 2010-2015 to 48.8 per 1000 , the same level of the 2000-2005 interval period. It is expected to continue decreasing to reach 2.3 migrants per 1000 in 2040-2045 and will remain at this level in 2045-2050.

According to Qatar Permanent Population Committee (QPPC) (2012), the country's population grew at 18.9\% in 2008 before it sharply declined to $1.4 \%$ in 2011 . This highly variable growth has been the hallmark of Qatar's population growth trends since the 1970's. Previously, the growth rate of the population in Qatar had decreased markedly between the periods of 1980-1985 to 1990-1995, from 10.12 to 1.01 percent respectively (UN, World Population Prospects: The 2012 Revision 2012). Due to the increasing demand for expatriate workers in various fields, especially in construction sector to ensure the country meets the requirements of Qatar World Cup, QPPC expects that population growth in Qatar will continue to rise at least until 2022. However, It is projected that the growth rate of the Qatari population will continue to decrease again and will reach 0.15 per cent for the period 2045-2050 (ESCWA, 2009).

This rapid population growth had also given Qatar undoubtedly one of the strangest population pyramids of all times. The country is the second-most disproportionately male in the world and is only surpassed by the United Arab Emirates. Overall, sex ratio is about 200 males to every 100 females. This ratio is exacerbated by the overwhelming disproportion between the ages of 15 and 45, with nearly $80 \%$ of the total population in this age group being males. This is the result of the fact that most immigrants come to Qatar as singles who leave their families behind.

Figure 1 shows the change that the population pyramid of Qatar has gone through since 1950. The top pyramid shows the age and gender of Qataris in 1950 while the middle one shows the population structure in 2010. The bottom pyramid gives the projected structure of the Qatari population in 2050. In 1950, as the first chart shows, Qatar's demographic structure was typical of developing countries, a broad base of young people under 15 years of age, narrowing uniformly with progressively older demographics, whereby few made it to advanced aging. Furthermore, the structure was quite evenly gender balanced. By 2010, the broad base at the bottom had narrowed considerably, indicating a sharp decline in the relative share of the cohort of those who are under 15 years of age. There is also a clear bulge in the number of 30 to 50 year olds and the gender balance of 1950 has been heavily tipped towards males with much less females (women scarcity). In 2050, there will be a slight decrease in the 30 to 50 years old cohort, a growing proportion of higher-aged demographics, in particular the 60 or 65 year bracket, and a continued scarcity of females at all age cohorts except the younger ones below 15 or 20 years of age. This is even true at the upper age cohorts which are very uncharacteristic of normal demographic structures, as women life expectancy is generally higher than that of men. Such changes cannot be accounted for except by migration. However, migration comes with a social price tag. Table 3 gives the following sex ratios in 2014 broken down by broad age groupings.

Table 3. Age Grouping by Gender

\begin{tabular}{cccc}
\hline Years & $\begin{array}{c}\text { Male } \\
(\mathrm{N})\end{array}$ & $\begin{array}{c}\text { Female } \\
(\mathrm{N})\end{array}$ & $\%$ \\
\hline $0-14$ & 134477 & 130640 & 12.5 \\
$15-24$ & 208278 & 75889 & 13.4 \\
$25-54$ & 1228151 & 256099 & 69.9 \\
$55-64$ & 55386 & 16156 & 3.4 \\
65 and older & 11226 & 6858 & 0.9 \\
\hline
\end{tabular}

Source: CIA, the World Fact Book. Retrieved from 
https://www.cia.gov/library/publications/the-world-factbook/fields/2018.html\#qa

The influx of migrants brought other structural changes to Qatar. In 1950, Qatar was almost exclusively an Arab and Muslim society. Today, ethnically, Qatar is about 40\% Arabs, while both Pakistanis and Indians make up another 36\% evenly split between the two nationalities, 10\% Iranians, and 14\% from other ethnic backgrounds. Religiously, Qatar in 2004 was estimated to be $77.5 \%$ Muslims, 8.5\% Christians while others (including Hindu and other Indian religions) make about $14 \%$ of the population (CIA, The World Factbook, 2013). While Qatar cannot truly be referred to as a 'melting pot', such a large influx of migrants and ethnic diversity instigated wide-spread acculturation. Newer generations of Qataris are more open and more exposed to the outside world more than their predecessors, a considerable number of them speak English, with overall higher levels of educations than previous generations. The new generations are better educated - especially females - and they are technologically sophisticated.
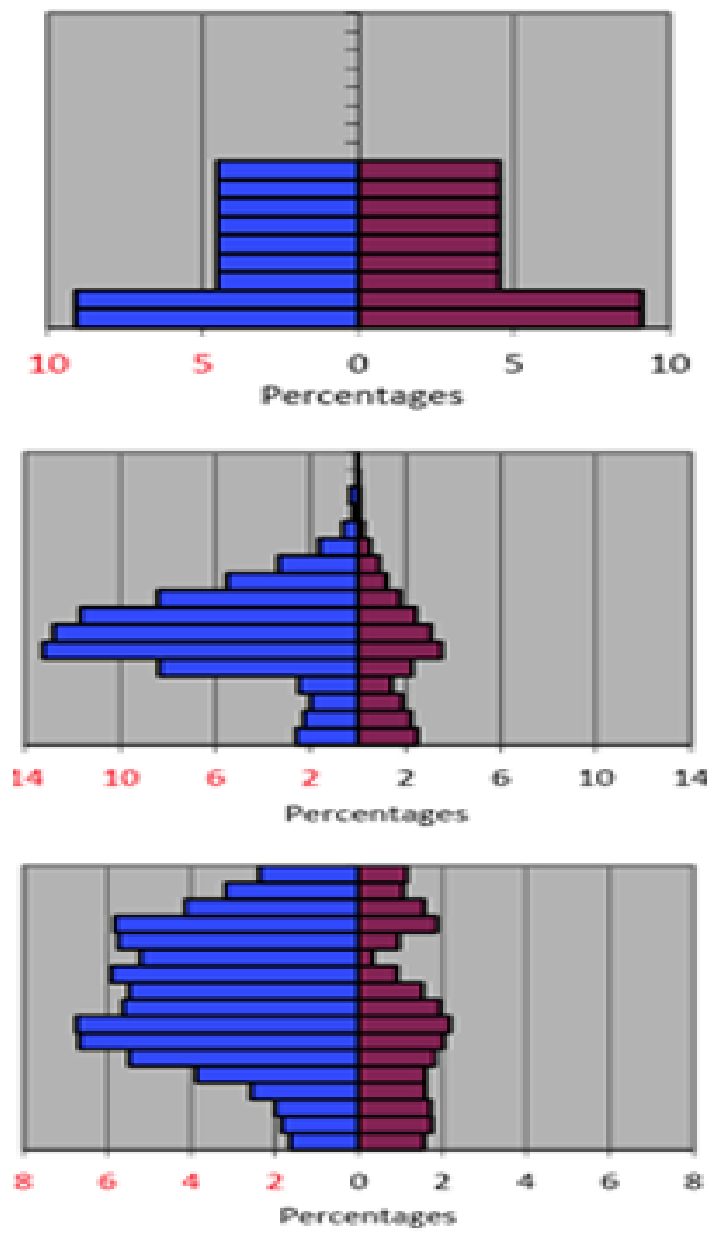

Figure 1. Changing population Pyramid of Qatar: 2010-2050

Source: ESCWA. (2009). Demographic Profile of Qatar. Retrieved from

http://www.escwa.un.org/popin/members/qatar.pdf

\section{Method Data source and limitations}

Given the current state of scientific knowledge and data availability about mixed marriage in Qatar, this study is essentially descriptive. Data from Qatar annual bulletins of vital statistics were analyzed to document the changing trends and patterns of mixed marriage among Qataris from 1985-2013. Annual bulletins are available on the Internet from the (QSA) for the years 1984 - 2013. The available data give information on marriage statistics for both spouses by nationality and gender only. Descriptive statistics, including frequencies and percentages were calculated and displayed in graphs to document the trends and patterns of mixed marriage amongst Qataris from 1985 up to 2013.

Although this research provides evidence-based results of the trends and patterns of mixed marriage among Qataris, it has some important limitations that warrant discussion. First, the annual bulletins of vital statistics provide a general 
picture of the trends and patterns of mixed marriage among Qataris, yet they lack comprehensiveness. It takes only legally married couples into account and do not include all the marriages outside Qatar or other types of marriages like almisyar /mut'ah urfi and summer marriage (see for example, Al- Khateeb, 2009; Al Nasr, 2011; El Feki, 2013, pp 181-183; El Gawahry, 1995). Second, the definition of mixed marriage (by nationality) is very narrow because it only gives us a partial view/perspective of the reality and does not take into account cultural, religious, and ethnic differences. Finally, the data is not detailed by nationality.

\section{Analysis and Results}

Qatar is a tribal society where tribal lineages are a strong determinant of social prestige, status, and power (Hanieh, 2011; El-Haddad, 2003). Therefore, marriage has always been for the most part endogamous, in which people tend to marry someone from the same social group and cultural background. Such practices help to strength group cohesion and solidarity (Gordon 1964), define group boundaries, maintain property within family lines, and highlight group's identity (Schwimmer, 2003). However, over the last few decades, enormous social changes has witnessed by the country touched upon all aspects of life, including patterns of marriage. In this respect, mixed marriages between Qataris males and females - and non-Qataris have been rising. Figure. 2 shows the change in the proportional share of endogamous and mixed marriages of the total number of Qataris' marriages. The results indicate that although endogamous marriage is still the main favored marriage pattern in Qatar, whereby it accounted for 76.9\% in 2013, mixed marriages increased in absolute number and almost doubled their relative share of all marriages of Qataris in comparison to where it stood in 1995. With the exception of the interval period of 1985-1990, where mixed marriages among Qataris witnessed a drop of four percentage points, the proportional share of mixed marriages have systematically increased and reached $23.1 \%$ in 2013 . Viewed comparatively, these rates are higher than their counterpart in the USA, Europe, Lebanon, and Kuwait, and less than they are in United Arab Emirates and Bahrain.

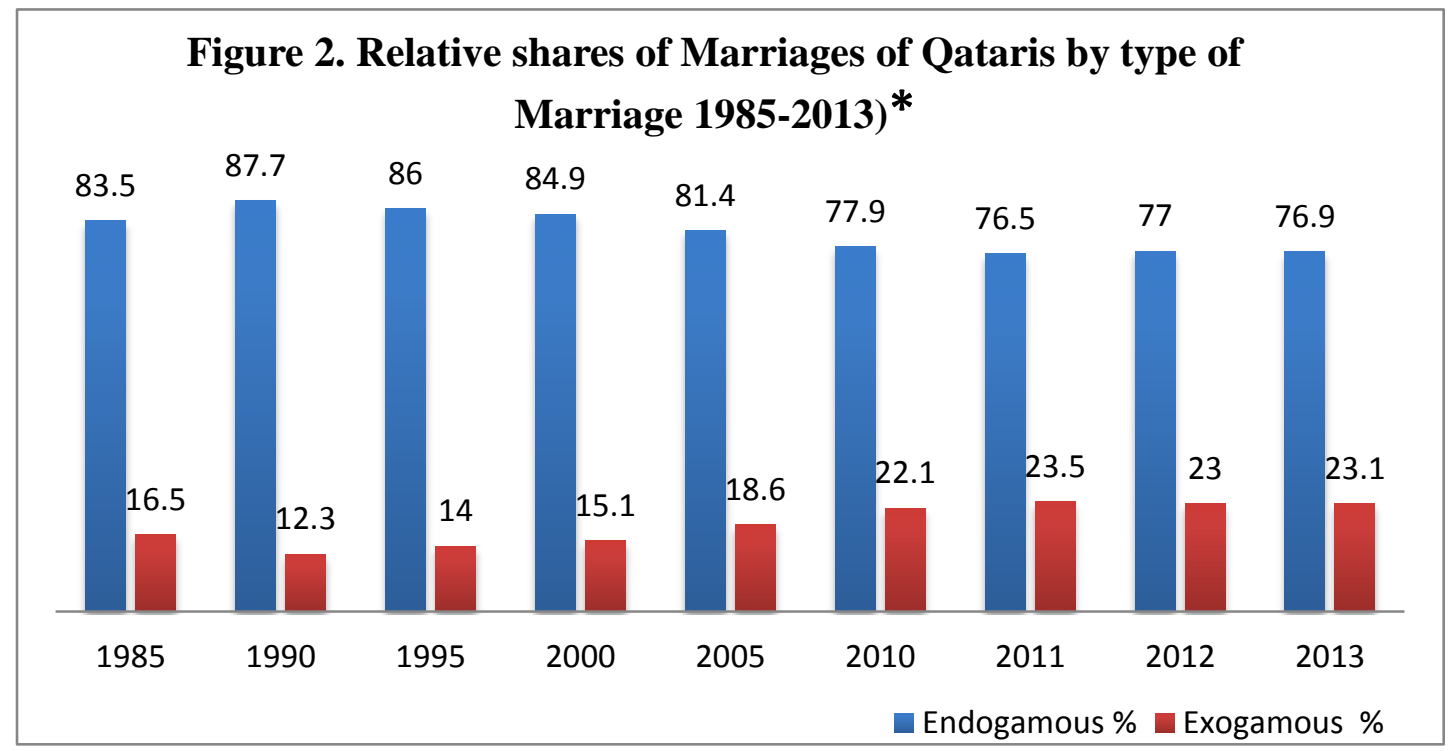

* Does not include mixed marriages among foreign population in Qatar. The original tables provide data at the regional level about spouses' nationality at the regional level as well.

Source: calculated by the authors from State of Qatar Annual Vital Statistics, Marriage and Divorce for the corresponding years. Available on the

Internet at: http://www.qix.gov.qa/portal/page/portal/qix/subject_area/Publications?subject_area=289.

The unprecedented trends for exogamous marriage prevalent in the above graph can probably be explained by several factors. Firstly, this is resultant from the rising cost of marrying a Qatari female, which may be attributed to conspicuous consumption behavior upon which Qatari brides and their families insist on excessively high bride wealth (Mahr) even in cases where brides and grooms are blood relative or cousins. To the best of our knowledge, there has not been a study that addressed marriage cost in Qatar in details. Secondly, Qatari females are increasingly becoming more educated than their male counterparts, making it more difficult for them to find a proper match and in turn pushing Qatari males away from marrying within their own native demographics. Another factor that comes into play is that Qatari men, in the most part favor a female with no marital history, even in the case of - though relatively declining second marriage. In such cases of second marriage, Qatari males still have to compete with non-Qatari males, who are less repulsed by the idea of marrying a divorcee, especially if she is a Qatari as that might garner some material 
advantages. Furthermore, state policy in Qatar is more tolerant towards males marrying other nationalities than it is towards females doing the same and so is the society at large, though males still have to obtain state permission from the Ministry of Interior to do so.

Figure 2 displays the change in the proportional share of mixed marriages of the total number of Qataris' marriages by gender of the spouse. The general trend indicated by the data is that Qatari females were marrying from foreign nationals in higher percentages than Qatar males during the entire period, with the exception of the interval period of 2000-2005. During this period the proportion of Qatari males who opted for mixed marriage outweighed their female counterparts. In 2013 as well, the two genders broke almost even with a minimal slight edge for Qatari females. Looking at the changing trends for each gender, the data shows that for the entire concerned period the relative share of Qatari females mixed marriages have remained almost constant where it stood at $11.8 \%$ in 1985 and $11.4 \%$ in 2013. Furthermore, it had also dipped during the interval periods of (1990-2005) where it averaged about 7.7\%. Since 2010, it witnessed a sudden rise of about $3.1 \%$ where it reached $11.6 \%$ of all Qatari females' marriage cases, compared to its level of $8.5 \%$ in 2005, and stayed close to that level until 2013. By comparison, Qatari males relative share of mixed marriages have systematically increased during the period covered by about 7 percentage points between 1985 to reach $11.7 \%$ in 2013.



Source: calculated by the authors from State of Qatar Annual Vital Statistics, Marriage and Divorce for the corresponding years. Available on the Internet:

http://www.qix.gov.qa/portal/page/portal/qix/subject_area/Publications?subject_area=289

Who do Qataris opt to marry? In other words, from which nationalities or regions do Qataris who choose mixed marriage select their spouses? Generally, Qatari citizens are still overall in favor of marrying someone from other GCC states, followed by other Arab countries. Figure 4 shows that in 2013 12.1\% of Qataris married a partner from the GCC area, followed by other Arab countries (8\%) respectively, while only (3\%) of Qataris married a partner from non- Arab countries. This is due largely to the cultural and religious similarities between the Arab countries in general. People in general tend to marry someone similar to them in terms of culture, education, religion, and status. Further, the preference of marrying a spouse from the other GCC countries is an indication of maintaining the tribal organization across borders where tribal lineages are a strong determinant of social status and identity, especially in the GCC Area. This clearly indicates that mixed marriage, despite its liberal manifest appearance, in the GCC countries in general and Qatar in particular functions to reproduce traditional social structures. 


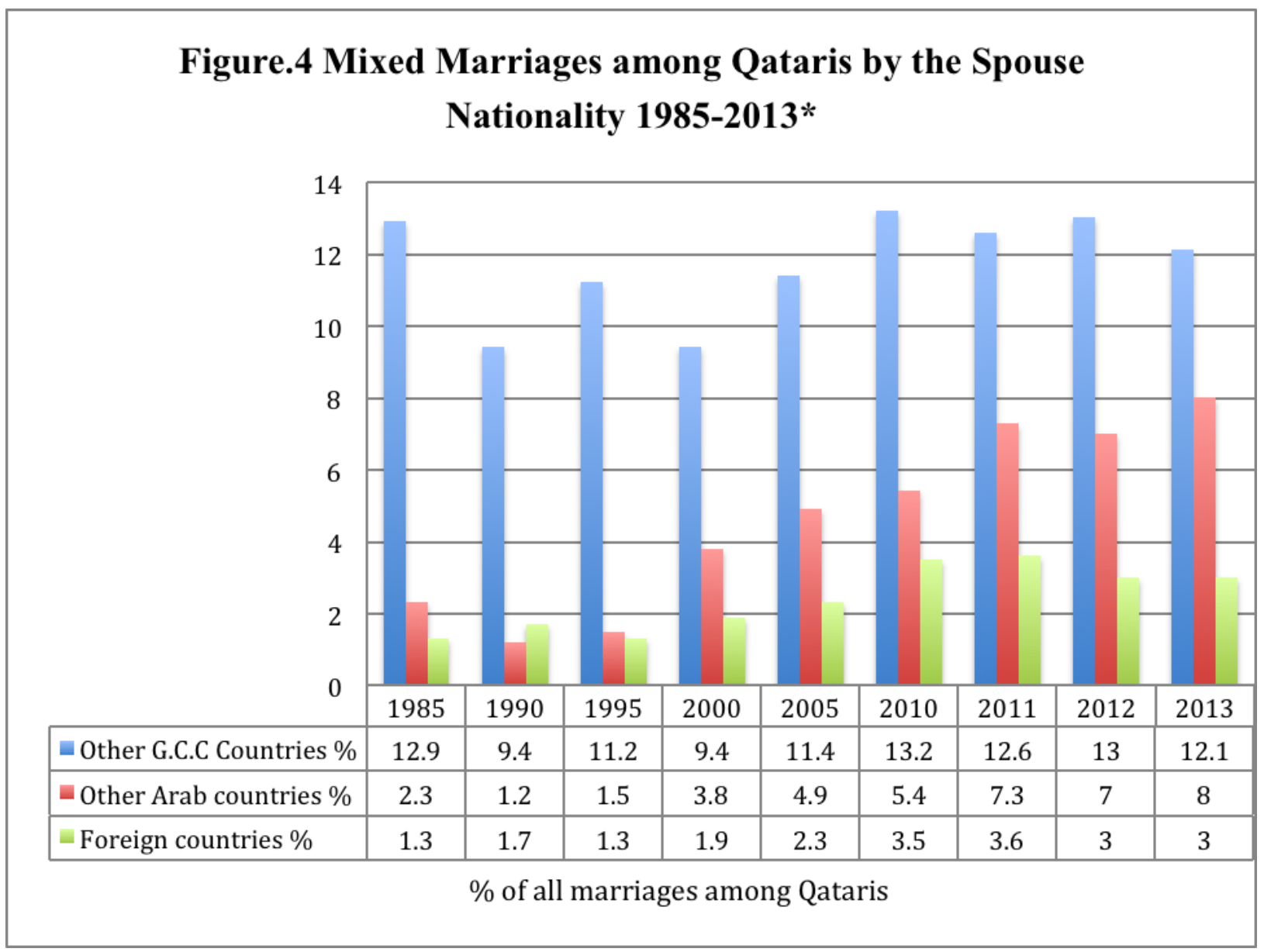

Source: calculated by the authors from State of Qatar Annual Vital Statistics, Marriage and Divorce for the corresponding years. Available on the Internet:

http://www.qix.gov.qa/portal/page/portal/qix/subject_area/Publications?subject_area=289

Although Qatari citizens living in mixed marriages are more likely to marry a partner from the other GCC states (Khaliji) -literary meaning a citizen of the GCC countries- followed by other Arab countries, there are some gender differences. As shown in figures 4 and 5, the general pattern that emerges from the data indicates that Qatari females are more likely than Qatari males to marry someone from other GCC countries. From 1985 to 2010, Qatar males tended to marry someone from other GCC countries. However, Qatari males started turning to non-GCC Arabs since 2011 whereby it reached about 5.3\% in 2013, which is five time higher than their share in 1985 (1\%). Mixed marriages between Qatari females and a non-Qatar GCC citizens, on the contrary, reached about 7.7\% in 2013, less than it was in 1985 (9.9\%). A possible explanation is that Qatari males seek a foreign spouse abroad due partly to the high cost of marriage and dowries (Fargues \& Francoise, 2015; Al-Othman, 2013; Sheikh, 2005; Al-Nasser, 2005 and 1995). Therefore, it is logical that they turn to cheaper destinations than the GCC countries. Qatari females, in contrast, would seek a husband of equivalent standard of wealth, education, and descent as their own. Women have a strong stake in retaining the purity of descent and their feeling of ethnic belonging (Fargues \& Francoise, 2015). Additionally, it is easier to marry someone from the GCC countries because it does not require an official permission to marry a GCC citizen. 




Source: calculated by the authors from State of Qatar Annual Vital Statistics, Marriage and Divorce for the corresponding years. Available on the Internet:

http://www.qix.gov.qa/portal/page/portal/qix/subject_area/Publications?subject_area=289 


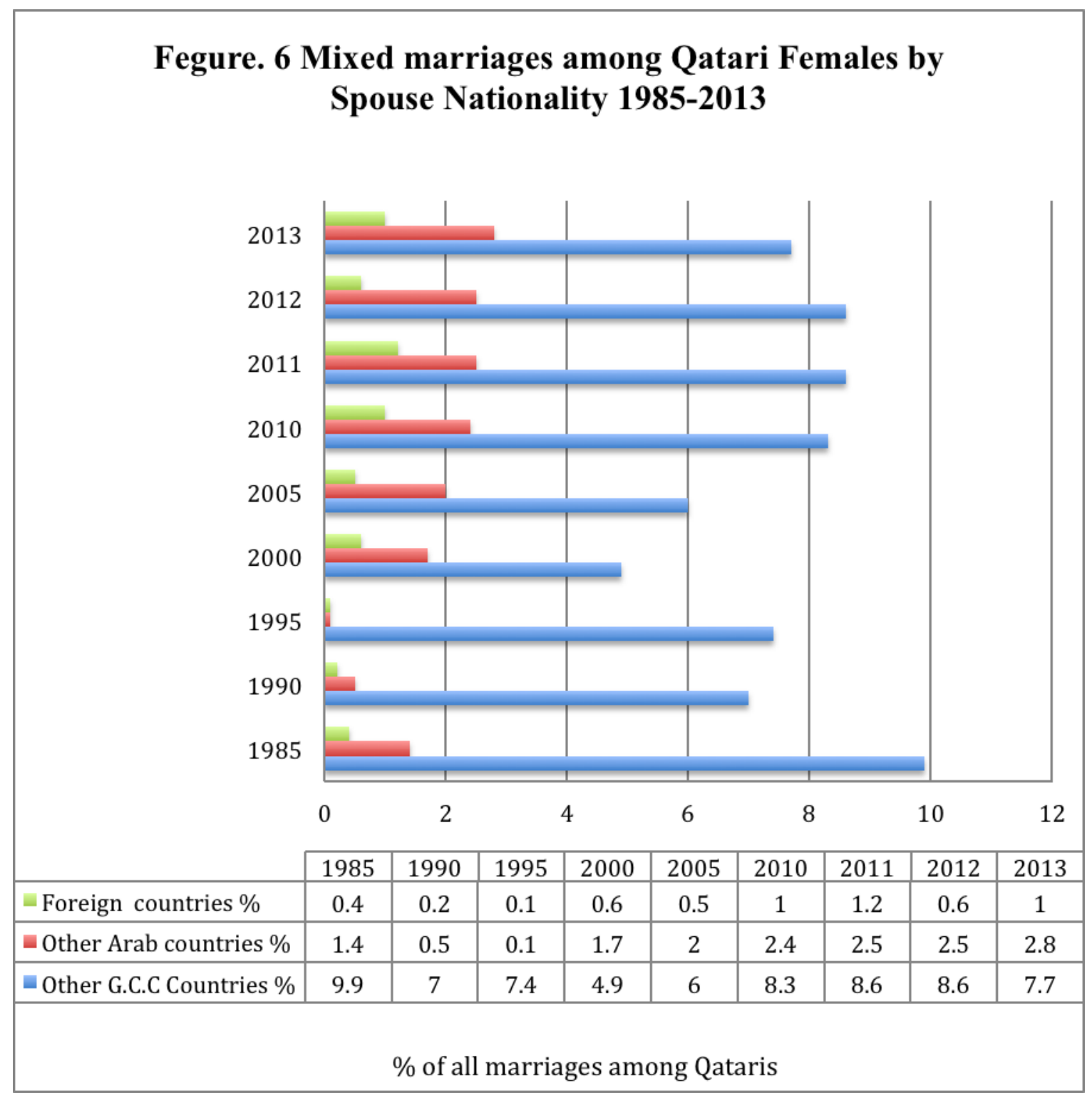

Source: calculated by the authors from State of Qatar Annual Vital Statistics, Marriage and Divorce for the corresponding years. Available on the Internet:

http://www.qix.gov.qa/portal/page/portal/qix/subject_area/Publications?subject_area=289

\section{Conclusion and Policy Recommendations}

The purpose of the present study is to analyze and outline the trends and patterns of mixed marriage among Qataris for the period 1985-2013. Although endogamous marriage (Qatari males married to Qatari females) is still the main marriage pattern among the Qatari population, mixed marriage in Qatar is on the rise. Mixed marriage among Qatari males compared to Qatari females has increased systematically since 1985, despite the fact that mixed marriage among females compared to males was much higher in number, with the exception of the interval period of 2000- 2005, and 2013 where mixed marriage among Qatari females witnessed a drop.

In mixed marriages, Qataris are still overall in favor of marrying someone from other GCC regions, followed by other Arab countries. However, there are some gender differences, where Qatari females are more likely than males to marry someone from other GCC areas. Qatari males in the last few years tend to marry from outside the GCC, mainly from other Arab countries.

The continuous growth in mixed marriage among Qataris has social, cultural, demographic implications for the Qatari families and society that need to be a central focus for family policy. . For example, increase in mixed marriage rate 
would likely to increase the rate of never- married women in Qatar. According to Qatar Statistics Authority (QSA) data, $19.6 \%$ and $12.3 \%$ of women aged 30-34 years and 35-39 years were never-married in 2004 compared to about $21 \%$ and $17 \%$ in 2010 respectively (Ucar, Al Harami and Leet, 2011). Ucar, Al Harami and Leet (2011) further reported that the tendency of Qatari males to marry non Qatari women combined with the negative attitudes towards Qatari women who marry non-Qatari men also contribute to increase women celibacy. This in turn will lead to a decline in Qatari women fertility levels over time. In this vein, it is noted that the total fertility Rate in Qatar has dropped from 5.45 children per woman in 1980-1985 to 2.21 children per woman in 2005 -2010. Projections show that total fertility will decline further to reach 2.05 (Replacement level fertility is 2.1) children per woman in 2010 - 2015 and expected to keep on declining to reach 1.67 children per woman in 2045-2050 (ESCWA, 2009).

A number of policy recommendations might be suggested here, such as developing a national plan aiming at public awareness about the need to reduce the size of dowries and the high cost of marriage; awareness campaigns aimed at encouraging and motivating young Qatari males to marry Qatari females, and ensure all available resources for them through accelerating the creation of a marriage fund that would encourage Qatari males to marry Qatari females and reduce the burden cost of marriage and dowries (State of Qatar Ministry of Development Planning and Statistics, 2012). This in turn will increase the proportion of Qatari citizens among the total population to ensure an improved balance in the population's composition.

Future research should address the attitudes of the family and Qatari society toward mixed marriage; the causes and the consequences of mixed marriage on individuals, familial and societal levels. In addition, the specificity of the socio-economic and demographics of Qatar, where lineages cross-cut with class boundaries under conditions of globalization and small indigenous population, calls for a fresh perspective to reach a proper understanding of the phenomenon of mixed marriage in the country. Thus, a deeper analysis of the political economy of the country in general and that of mixed marriage in the context of the process of rapid social change must be taken into account.

\section{Acknowledgment}

This publication is made possible by the support of Georgetown University School of Foreign Service in Qatar, Center for International and Regional Studies, through its Qatar Foundation Agreement.” and funded by Georgetown university.

This paper is based on going project on mixed marriage among Qataris led by Dr. Mohamad Mohieddin. An earlier version of this paper was presented at Doha International Family Institute First International Conference on Family "Family in an Age of Transition: Resilience and Challenges" Doha, May 3-4, 2015 and at the 5th LCSR Summer School "Introduction to Factorial Design and Data Visualization with R", July 25 - August 3, 2015 - Higher School of Economics, Voronovo, Moscow region.

\section{References}

Aldridge, D. P. (1973). The changing nature of interracial marriage in Georgia: a research note, Journal of Marriage and the Family, 35, 641-642.

Al Feki, S. (2013). Sex and the Ciitadel: Intimate Life in a Changing Arab World. London: Chatoo and Windus/

Al Khateeb, S. (2009). The Misyar Marriage in Saudi Arabia. Paper presented to The International Symposium of the Supreme Constitutional Court, Egypt on The Urfi Marriage: Validity and Implications in Collaboration with Konrad Adenauer Stiftung, Cairo: 14-15 November.

Al-Naqeeb, K. (1990). State and Society in the Gulf and Arab Peninsula: A Different Perspective. (Translated by L. M. Kenny and Amended by Ibrahim Hayani). London: Routledge.

Al-Nasr, T. J. (2011). Gulf Cooperation Council (GCC) Women and Misyar Marriage: Evolution and Progress in the Arabian Gulf. Journal of International Women's Studies, 12(3), 43-57.

Al-Nasser, F. (2005). Sociological interpretation of Non-homogenized marriage in Kuwaiti society Journal of the Gulf and Arabian Peninsula Studies, 125, 11-53. (In Arabic).

(1995). Kuwaiti attitudes towards marriage from non-Kuwaiti. Annals of the Faculty of Arts, Kuwait University, 15(140), 7-79. (In Arabic).

Al-Othman, H. (2013). Emirati Youth Attitudes toward Marriage to Non-Locals: A qualitative and Quantitative Study. Journal of King Saud, Riyadh, 25(1), 1-26. (In Arabic).

Alrouh, H., Ismail, A., \& Cheema, S. (2013). Demographic and health indicators in Gulf Cooperation Council nations with an emphasis on Qatar, Journal of Local and Global Health Perspectives, 3, 1-6. Retrieved from http://dx.doi.org/10.5339/jlghp.2013.3 
Bassard, J. H. (1939). Nationality and Nativity as Factors in Marriage. American Sociological Review, 4(6), 792-798.

Becker, G. S. (1973). A theory of marriage: Part I. Journal of Political Economy, 81(4), 813-46.

Bener, A. (2012). Consanguineous Marriages and their Effect on Common Diseases in the Qatari population in Genetic Disorders in the Arab World Qatar. Retrieved from http://www.cags.org.ae/cb405c2.pdf.

Burma, J. H. (1963). Interethnic Marriage in Los Angeles, 1948-1959. Social Forces, 42, 156-165.

CIA, The World FactBook. https://www.cia.gov/library/publications/the-world-factbook/fields/2018.html\#qa

Coleman, D. A. (1994). Trends in fertility and intermarriage among immigrant populations in Western Europe as measures of integration. Journal of Biosocial Science, 26, 107-136.

Collet, B. (2011). Mixed couples in France. Statistical facts, definitions, and social reality. Retrieved from www.raco.cat/index.php/Papers/article/download/248498/332622.

Dachsler, J. (1921). Intermarriage in New York City: A Statistical Study of the Amalgamation of European Peoples . In Lanzieri, G. (2012). Mixed marriage in Europe: 1990-2010. www.academia.edu/2565558/Mixed_Marriages_in_Europe_1990-2010 .

De Bel-Air, F. (2014). Demography, Migration and Labor Market in Qatar: Explanatory Note. Gulf. Migration Policy Center- Gulf Research Center, The European Institute. Retrieved from http://cadmus.eui.eu/bitstream/handle/1814/32431/GLMM_ExpNote_08-2014.pdf?sequence=1

El-Gawhary, K. (1995). Sex Tourism in Cairo". Middle East Report. Vol. 25: 5.September-October. Retrieved from http://www.hartfordhwp.com/archives/32/021.html

El-Haddad, Y. (2003). Major Trends Affecting Families in the Gulf Countries. Retrieved from www.un.org/esa/socdev/family/Publications/mtelhaddad.pdf

ESCWA. (2009). The Demographic Profile of Qatar. Retrieved from http://www.escwa.un.org/popin/members/qatar.pdf

Fargues, P., \& Francoise, D. B. (2015). Migration to the Gulf States: The Political Economy of Exceptionalism. In Diego, A., Arcarazo, A., \& Wiesbrock, A (ed). Global Migration: Old Assumptions, New Dynamics. Retrieved from https://books.google.com/books?isbn=1440804230.

Garcia, D. R. (2006). Mixed Marriages and Transnational Families in the Intercultural Context: A Case Study of African Á/Spanish Couples in Catalonia. Journal of Ethnic and Migration Studies, 32(3), 403 - 433.

Goli, S., Singh, D., \& Sekher, T. V. (2013). Exploring the myth of mixed marriages in India: Evidence from a nation-wide survey. Journal of Comparative Family Studies, 44(2), 193-206.

Gordon, M. M. (1964). Assimilation in American life: The role of race, religion, and national origins. New York, NY: Oxford.

Hanieh, A. (2011). Capitalism and Class Formation in the Gulf Arab States. London: Palgrave Macmillan.

Harmsen, C. N. (1999). Cross-cultural marriages. Department of population. Statistics Netherlands. Retrieved fromhttp://www.cbs.n1/NR/rdonlyres/163A2B50-3EAB-49F1-B3AB-686892B5108F/0/crossculturalmarriages.pdf.

Honeycutt, M., Lane, R., Pea,U., Taylor, A., \& Vande, J. (2005). Attitudes toward Interracial Marriage and Factors Which Influence the Choice to Enter an Interracial Relationship. Retrieved from www.unc.edu/ ldpearce/soci30/group\%20project/group5.doc .

Hopper, M. S. (2008). Slaves of One Master: Globalization and the African Diaspora in Arabia in the Age of Empire. Proceedings of the 10th Annual Gilder Lehrman Center International Conference at Yale University Slavery and the Slave Trades in the Indian Ocean and Arab Worlds: Global Connections and Disconnections, November 7-8, Yale University, New Haven, Connecticut: 29-32.

Information-International. (2013). Mixed marriage Contracts.



Jakobsen, M. (1956). Social Effects of the Educational Revolution in Qatar: A Gender Perspective Master Thesis in Arabic Language Department of Foreign Languages University of Bergen. Retrieved from https://bora.uib.no/bitstream/handle/1956/7299/69631686.pdf?sequence=1

Jo-Pei, T. (2012). Inter-Ethnic and Mono-Ethnic Families: Examining the Association of Parenting and Child Emotional and Behavioural Adjustment. Pertanika Journal of Social Science \& Humanities, 20(1), 165-178.

Kalmijn, M. (1998). Intermarriage and Homogamy: Causes, Patterns, Trends. Annual Review of Sociology, 24, 395-421. 
kingdom of Bahrain Central Informatics Organization. (2013). http://www.cio.gov.bh/cio_eng/Stats_SubDetailed.aspx?subcatid=604.

Kulu1, H., \& González-Ferrer, A. ( 2014). Family Dynamics among Immigrants and their Descendants in Europe: Current Research and Opportunities. European Journal of Population, 30, 411-435.

Lanzieri, G.(2012a). Merging populations- A look at marriages with foreign-born persons in European countries. Eurostat Statistics in Focus.

http://www.bing.com/search?q=Merging+populations+A+look+at+marriages+with+foreign-born+persons+in+Eur opean+countries\&src=IE-SearchBox\&FORM=IE8SRC .

Lanzieri , G. (2012b). Mixed Marriages in Europe, 1990-2010. www.academia.edu/2565558/Mixed_Marriages_in_Europe_1990-2010 .

Lanzieri , G. (2012c). The mixture as before. http://www.economist.com/blogs/feastandfamine/2012/07/mixed-marriages .

Layachi, A. (2013). Divorce in the Arab Gulf Countries: A major Challenge to Family and

Society. In, Abela, A., \& Walker, J. (Eds.). Contemporary Issues in Family Studies: Global Perspectives on Partnership, Parenting and Support in a Changing World.London: Wiley-Blackwell.

Lewis, R. (2014). Status of Interracial Marriage in the United States: A Qualitative Analysis of Interracial Spouse Perceptions. International Journal of Social Science Studies, 2(1), 16-25.

Lorimer, J, G. (1908). Gazetteer of the Persian Gulf, Oman and Central Arabia. Calcutta: Superintendent Government Printing (1908-15) Geogr. Translated into Arabic as Dalil al-Khalij (1971). Doha: Ali Ben Ali PrintShop. Retrieved from www. http://www.qdl.qa/en/archive/81055/vdc_100000000884.0x00014a .

Muttarak, R. (2010). Explaining trends and patterns of immigrants' partner choice in Britain Journal of Family Research, 22, 37-64.

Nave, A. (2000). Marriage and the maintenance of ethnic group boundaries: the case of Mauritius". Ethnic and Racial Studies, 23(2), 329-352. http://dx.doi.org/10.1080/01419870032907.

Neyrand, G., \& M'Sili, M. (1998). Mixed Couples in Contemporary France. Marriage, Acquisition of French Nationality and Divorce. Population: An English Selection, 10(2), 385-416

O’Donoghue, M. (2004). Racial and Ethnic Identity Development in White Mothers of Biracial, Black-White Children, Affilia, 19(1), 68-84.

Oganesyan , M. (2014). Mixed Marriages in Georgia: Trends and implications. Caucasus Analytical Digest,64, 14-17. www.css.ethz.ch/publications/pdfs/CAD-64-14- 17.pdf

Panunzio, C. (1942). Intermarriage in Los Angeles, 1924-1933. American Journal of Sociology, 47, 690-701.

Petersen, L.R. (1986). Interfaith Marriage and Religious Commitment among Catholics. Journal of Marriage and Family, 48(4), 725-735.

Qatar Statistical Authority (2008). Analytical Summery Labour Force Sample: Survey Results, 2008. http://www.qsa.gov.qa/eng/surveys/labor_force_analytical_summary_2008.pdf.

Qatar Statistical Authority (1985-2013). Annual Vital Statistics,http://www.qix.gov.qa/portal/page/portal/qix/subject_area/Publications?subject_area=289

Qatar Statistics Authority. (2015). Population structure. 30 April. http://www.qsa.gov.qa/eng/populationstructure.htm.

Qian, Z. (2005). Breaking the Last Taboo: Interracial Marriage in America. Contexts, 4(4), 33- 37, ISSN 1536-5042, electronic ISSN 1537-6052.

Sandridge, A. L., Takeddin, J., AL-kaabl, E., \& Frances, Y. (2010). Consanguinity in Qatar: Knowledge, Attitude and Practice in a Population Born Between 1946 and 1991. Journal of Biosocial Science, 42, 59-82 http://dx.doi.org/10.1017/S002193200999023X.

Schwimer, B. (2003). Endogamy. Retrieved from https://www.umanitoba.ca/.../endogamy.html .

Sheikh, M. (2005). Marriages to Foreign Women and its Security and Social returns In Alothman, H. (2013). Emirati Youth Attitudes toward Marriage to Non-Locals: A qualitative and Quantitative Study. Journal of King Saud, Riyadh, 25(1), 1-26. (In Arabic).

Singh, D., \& Goli, S. (2011). Exploring the Concept of Mixed Marriages in Indian and selected states: First Time Evidences from Large Scale Survey. Retrieved from http://paa2011.princeton.edu/papers/111966 
State of Kuwait Central Statistical Bureau. (2013). Retrieved from http://www.csb.gov.kw/Default_EN.aspx.

State of Qatar, Permanent Population Committee. (2012). Qatar Population Status 2012.. Retrieved from http://www.gsdp.gov.qa/portal/page/portal/ppc/PPC_home/ppc_news/ppc_files_upload/populations_status_2012_e n.pdf

Tarabey, L. (2013). Family Law in Lebanon: Marriage and Divorce among the Druze. London: I. B. Tauris.

UAE National Bureau of Statistics. (2013). http://www.uaestatistics.gov.ae/EnglishHome/tabid/96/Default.aspx

Ucar, P., Al Harami, B., \& Leet, R. (2011). Trends and Patterns in Qatari Family Formation and Childbearing. Retrieved from http://sesri.qu.edu.qa/sites/default/files/Common/Conferences/2011/day1/pinar.pdf.

United Nations. (2013). Human Development Index. Retrieved from http://hdr.undp.org/en/content/table-2human-development-index-trends-1980-2013.

United Nations. World Population Prospects: the 2012 Revision. New York: United Nation. Retrieved from http://esa.un.org/unpd/wpp/unpp/panel_indicators.htm

Varro, G., Strelff-Fenart J., \& Phillppe, C. (1994). Des familles dites mixtes, in Culltures croisees: In Neyrand, G ., \& M'Sili, M. (1998). Population: An English Selection, 10(2), 385-416.

Wang, W. (2012). The Rise of Intermarriage Rates, Characteristics Vary by Race and Gender. PEW Research Center. Social \& Demographic Trends: Washington, D. C.

http://www.pewsocialtrends.org/files/2012/02/SDT-Intermarriage-II.pdf.

Yee, C. (2012). How Minorities Perceive and React to Interracial Relationships: Qualitative,

Survey and Experimental Evidence from Asian American Men. Dissertation Abstracts International, 72(B).

\section{Notes}

Note 1: The 30 European countries include: Belgium, Bulgaria, the Czech Republic, Denmark, Germany, Estonia, Ireland, Greece, Spain, France, Italy, Cyprus, Latvia, Lithuania, Luxembourg, Hungary, Malta, the Netherlands, Austria, Poland, Portugal, Romania, Slovenia, Slovakia, Finland, Sweden, the United Kingdom, Iceland, Norway, and Switzerland.

Note 2:The mass production of cultured pearls in Japan had destroyed the pearl industry of the Gulf. In Bahrain, the annual revenue from pearl exports in 1906 was over 12 million rupees, and the industry employed over 17,000 men and 900 boats. By 1931, pearl revenue was down below 2 million rupees with roughly the same number of men employed and 500 boats. By 1936, however, pearl revenue was down below 700,000 rupees with 9,800 men from the island employed in the industry and 364 boats. Pearl captains (Nokhadha) and merchants who had formerly benefited from the labor of slave divers now found them burdens. Similar conditions must have prevailed in Qatar. For more details see, Hopper, M. S. (2008). Lorimer, estimated that the Qatari fleet of pearling around the early 1900's was composed of 817 boats employing about 13,000 persons in all of Qatar in addition to another 390 boats working in fishing and other activities. Assuming equal levels of productivity given the prevalent technology was the same, it can be estimated that income generated from pearling in Qatar ranged between a minimum of 9.2 million rupees if calculated based on the proportional size of the labor force employed in pearling and a maximum of about 10.9 million rupees when taking the number of pearling industry boats. This amounts to an average of 10 million rupees when taking both the size of the fleet and labor force into account. Assuming comparable decline, it means that by 1936 Qatar income from pearling had declined to an average of 585,000 rupees or about $94.2 \%$ decline in pearling income in 30 years. See, Lorimer, J. G. (1908): 1989-1990.

\section{(cc) $E Y$}

This work is licensed under a Creative Commons Attribution 3.0 License. 